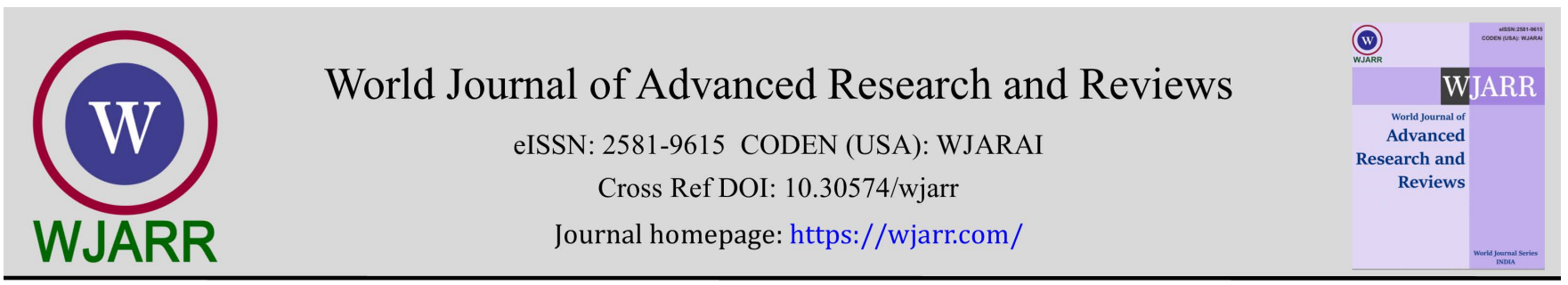

(RESEARCH ARTicle)

\title{
Safety and short-term outcomes of sleeve gastrectomy and Roux-en-Y gastric bypass following removal of adjustable gastric banding
}

\author{
Omar Thaher 1, ${ }^{*}$, Jamal Driouch ${ }^{1}$, Martin Hukauf ${ }^{2}$ and Christine Stroh 3 \\ ${ }^{1}$ Department of Surgery, Marien Hospital Herne, Ruhr-Universität Bochum, Hölkeskampring 40, 44625 Herne, Germany. \\ 2 StatConsult Society for Clinical and Health Services Research mbH, Am Fuchsberg 11, 39112 Magdeburg, Germany. \\ ${ }^{3}$ Department of General, Abdominal and Pediatric Surgery, Municipal Hospital, Straße des Friedens 122, 07548 Gera, \\ Germany.
}

World Journal of Advanced Research and Reviews, 2021, 10(03), 358-369

Publication history: Received on 23 May 2021; revised on 25 June 2021; accepted on 27 June 2021

Article DOI: https://doi.org/10.30574/wjarr.2021.10.3.0293

\begin{abstract}
Background: The practice of bariatric surgery was studied using the German Bariatric Surgery Registry (GBSR). The focus of the study was to evaluate whether revision sleeve gastrectomy (R-SG) or Roux-en-Y Gastric Bypass (R-RYGB) has a major benefit in terms of perioperative risk in patients after failed Adjustable Gastric Banding (AGB).

Methods: The data collection includes patients who underwent SG or RYGB as revision surgery after failed AGB between 2005 and 2019. Outcome criteria were perioperative complications, comorbidities, 30-day mortality, and operative time.

Results: The study analyzed data from 1395 patients after revision SG and RYGB. 907 patients after R-RYGB, and 488 after R-SG. Intraoperative and overall postoperative complication rates were not significantly different between the two groups ( $\mathrm{p}=0.321$ and 0.621 ). The specific postoperative complication rate was significantly lower in $\mathrm{R}-\mathrm{SG}$ than in $\mathrm{R}-$ RYGB ( $p=0.049)$. The mean operative time differed significantly between the two groups in favor of R-SG (160.3 min vs. 128.3 min; $p<0.001)$. There was no significant difference in 30-day mortality between the two groups ( $\mathrm{p}=0.952)$.

Conclusion: The study shows that R-SG and R-RYGB are safe and feasible as revision procedures and have acceptable complication and mortality rates. However, in our study, we cannot make a recommendation in favor of any of the surgical methods. Proper patient selection is essential to avoid possible adverse effects. Concerning the long-term results, further studies with higher methodological quality are necessary.
\end{abstract}

Keywords: Bariatric surgery; Sleeve gastrectomy; Gastric bypass; Gastric banding; Complications; Comorbidities

\section{Introduction}

Obesity is an enormous global chronic health problem [1]. Its prevalence has tripled since the 1980s, and there are now over 1.9 billion obese people worldwide [2]. In children and adolescents, obesity has increased significantly in recent years [3]. Comorbidities and obesity-associated diseases lead to increasing morbidity and mortality, as well as increasing reduction in quality of life and impairment due to severe psychopathological disorders [4, 5]. In recent decades, bariatric surgery, regardless of the type of surgical procedure used, has shown great success in changing BMI compared with the results of non-surgical procedures [6]. Bariatric surgery is recommended for people who have not been able to achieve permanent \%total weight loss (TWL \%) with non-surgical methods [7]. A well-known bariatric

\footnotetext{
${ }^{*}$ Corresponding author: Omar Thaher

Department of Surgery, Marien Hospital Herne, Ruhr-Universität Bochum, Hölkeskampring 40, 44625 Herne, Germany.

Copyright (C) 2021 Author(s) retain the copyright of this article. This article is published under the terms of the Creative Commons Attribution Liscense 4.0.
} 
surgical procedure for the treatment of severe obesity is adjustable gastric banding (AGB) [8]. Unfortunately, AGB requires revision surgery in $20-60 \%$ of cases due to band slippage, chronic esophagitis, erosion, pouch dilation, infection, discomfort, and complications (i.e., vomiting, infection or positioning problems, pain after eating, or difficulty swallowing) or failure with significant TWL\% $[9,10,11,12]$. Here, surgeons should use other surgical procedures to achieve tremendous TWL\% and effective complication management. The most used surgical procedures are gastric bypass (RYGB) and sleeve gastrectomy (SG) [13]. Several clinical trials investigated the effect of both surgical procedures in terms of BMI change and complication management as revision surgery after failed gastric banding [13, $14,15,16]$. Our study aims to show the safety and feasibility of revision surgery from AGB to RYGB and SG.

\section{Material and methods}

This retrospective study with prospectively collected data analyzed data from patients who underwent revisional RYGB surgery (R-RYGB) and revisional sleeve gastrectomy (R-SG) between 2005 and 2019 after AGB failure. Processed data from the export of the Quality Assurance Study for Surgical Therapy of obesity of the German Bariatric Surgery Registry (GBSR) of the Institute for Quality Assurance in Surgical Medicine of the Otto-von-Guericke University Magdeburg were used. Only interventions that were validated as plausible at the time of data export were included in our analysis. Plausibility checks were performed when preparing obesity data for annual reports. Data included demographic and medical aspects such as age, sex, comorbidities, change in BMI $\left(\mathrm{kg} / \mathrm{m}^{2}\right)$, 30-day mortality, operative time, and intra- and postoperative complications.

All analyzes were performed by StatConsult GmbH using SAS 9.4 software (SAS Institute Inc., Cary, NC, USA). As this was an exploratory analysis, the overall significance level of $5 \%$ was deliberately used, i.e., no correction for multiple testing is applied, and any $\mathrm{p} \leq 0.05$ corresponds to a significant result.

In our study, data from 1395 patients were analyzed. In this study, we focused only on the results of the revision procedures (R-SG and R-RYGB) according to AGB. For both procedures, we did not discuss and analyze the reasons for band removal and reoperation. The distributions of the (quasi-)continuous variables, the mean and standard deviation (STD), were reported in the results tables. For categorical variables, relative (\%) frequencies were presented in contingency tables. For categorical variables, the chi-square test was used for unadjusted analyzes of the procedures (R-SG vs. R-RYGB). For continuous variables, analysis of variance (ANOVA) was used. Analyzes on non-normally distributed data (operative time) were performed with log-transformed values.

Our analysis included various medical aspects, such as intraoperative and postoperative complication rates, mortality, and operative time. In addition, the specific postoperative complications such as sepsis, abscess formation, bleeding requiring transfusion, bleeding requiring surgery, and anastomotic leakage after RYGB or staple line leakage after SG were investigated. Intraoperative complications such as splenic, biliary, hepatic, and vascular injuries, pneumothorax, gastric perforation and intraoperative bleeding were analyzed. Our study compared the short-term outcomes of revision surgery (R-SG vs. R-RYGB) after AGB. Long-term outcomes were not analyzed in this study.

We compared the outcome of patients after R-SG $(n=488)$ with those who underwent R-RYGB (n = 907). With one exception, the indication for R-SG and R-RYGB was not standardized and was not documented in our study. Because this is a registry data collection, we cannot describe the surgical steps for band removal and revision surgery. It depends on the surgeons and their expertise which method they use during the procedure. In our analysis, the type of surgery (laparoscopic vs. open approach) was not considered.

\section{Results}

We analyzed data from 1395 patients from 2005 to 2019; 907 patients underwent R-RYGB and 488 patients underwent R-SG (Table 1). 
Table 1 Distribution of patients according to demographic variables and surgical method

\begin{tabular}{|c|c|c|c|c|}
\hline & & R-SG & R-RYGB & p-value \\
\hline Age (y) & $\mathrm{n} /$ mean value $\pm \mathrm{STD}$ & $488 / 45.7 \pm 9.5$ & $907 / 46.1 \pm 10.1$ & 0.415 \\
\hline $\begin{array}{c}\text { BMI } \\
\mathrm{Kg} / \mathrm{m} 2\end{array}$ & $\mathrm{n} /$ mean value $\pm \mathrm{STD}$ & $488 / 45.8 \pm 10.7$ & $907 / 44.0 \pm 7.8$ & 0.001 \\
\hline \multirow{2}{*}{$\begin{array}{l}\text { Gender } \\
(\mathrm{m} / \mathrm{f})\end{array}$} & $\%$ & $27.3 / 72.7$ & $19.7 / 80.3$ & \multirow[t]{2}{*}{0.001} \\
\hline & (n) & $133 / 355$ & $179 / 728$ & \\
\hline \multicolumn{5}{|c|}{ Distribution of surgical method } \\
\hline & Method & R-SG & \multicolumn{2}{|c|}{ R-RYGB } \\
\hline & $\mathrm{N}$ & 488 & \multicolumn{2}{|c|}{907} \\
\hline & Total & \multicolumn{3}{|c|}{1395} \\
\hline
\end{tabular}

\subsection{Descriptive statistics and unadjusted analyses}

The continuous parameters of the perioperative course are shown in Table 1 for all patients who underwent R-RYGB and R-SG surgery. Here, there was a significant difference in the mean BMI between the two groups. Thus, the R-SG patients had a significantly higher BMI ( $45.8 \pm 10.7 \mathrm{~kg} / \mathrm{m}^{2} \mathrm{R}-\mathrm{SG}$ vs. $44 \pm 7.8 \mathrm{~kg} / \mathrm{m}^{2} \mathrm{R}-\mathrm{RYGB}$; p=0.001). However, there was no significant difference between the two groups in terms of mean age (R-SG $45.7 \pm 9.5$ years vs. $46.1 \pm 10.1$ in the R-RYGB; $\mathrm{p}=0.415$ ). In addition, we analyzed the percentage distribution of male patients who underwent bariatric surgery compared to female patients. We found that the number of female patients accounted for a significantly higher proportion than the number of male patients in both groups ([f/m] 72.7\%/24.3\% in R-SG and 80.3\%/19.7\% in R-RYGB; $\mathrm{p}=0.001)$.

The percentage distribution of total comorbidities was not significant between the two groups (78.7\% in R-SG group vs. $80.2 \%$ in R-RYGB group; $\mathrm{p}=0.517$ ). $26 \%$ of patients in the R-SG group had type 2 diabetes mellitus (T2DM) vs. 24.8\% in the R-RYGB group ( $\mathrm{p}=0.651$ ). The rate of arterial hypertension was $52.7 \%$ in the R-SG group and $48.6 \%$ in the R-RYGB group $(\mathrm{p}=0.150)$. Sleep apnea was diagnosed significantly more frequently in the R-SG group (18.4\%) than in the RRYGB group (12.8\%; $\mathrm{p}=0.005)$. The ASA classification showed a significant difference between the two groups. ASA II and III were significantly higher in R-RYGB than in R-SG (ASA II 45.7\% in R-SG vs. 47.2\% in R-RYGB, ASA III 42.6\% in RSG vs. $49.4 \%$ in R-RYGB; $\mathrm{p}<0.001$ ). Regarding pulmonary comorbidities and the incidence of pulmonary embolism, no significant difference was found between the two groups $(p=0.151$ and 0.881$)$. Other comorbidities such as degenerative spine disease (DSD), other cardiac and vascular diseases, varicoses, non-alcoholic steatohepatitis, nicotine abuse, degenerative skeletal diseases and gonarthrosis were also analyzed. There was a significant difference in DSD (42.8\% in the R-SG vs. $30.9 \%$ in the R-RYGB; p<0.001), degenerative skeletal disease $(22.7 \%$ in the R-SG vs. $17.8 \%$ in the R-RYGB; $\mathrm{p}=0.025)$ and reflux (13.7\% in the R-SG vs. $21.7 \%$ in the R-RYGB; $\mathrm{p}<0.001)$. No significant difference was found regarding other cardiac and vascular diseases $(p=0.934)$, varicoses $(p=0.301)$, non-alcoholic steatohepatitis $(p=0.670)$, nicotine abuse $(p=0.680)$ and gonarthrosis $(p=0.925)$. A summary of the comorbidities is shown in Table 2 .

Table 2 Distribution of patients according to comorbidities

\begin{tabular}{|c|c|c|c|c|c|c|}
\hline & & \multicolumn{2}{|c|}{ R-SG } & \multicolumn{2}{|c|}{ R-RYGB } & \multirow[t]{2}{*}{ p-value } \\
\hline & & $\mathbf{n}$ & $\%$ & $\mathbf{n}$ & $\%$ & \\
\hline \multirow[t]{4}{*}{ ASA } & ASA I & 40 & 8.2 & 23 & 2.5 & \multirow[t]{4}{*}{$<0.001$} \\
\hline & ASA II & 223 & 45.7 & 428 & 47.2 & \\
\hline & ASA III & 208 & 42.6 & 448 & 49.4 & \\
\hline & ASA IV & 17 & 3.5 & 7 & 0.8 & \\
\hline \multirow[t]{2}{*}{ Comorbidities } & Yes & 384 & 78.7 & 727 & 80.2 & \multirow[t]{2}{*}{0.517} \\
\hline & No & 104 & 21.3 & 180 & 19.8 & \\
\hline
\end{tabular}


World Journal of Advanced Research and Reviews, 2021, 10(03), 358-369

\begin{tabular}{|c|c|c|c|c|c|c|}
\hline \multirow{2}{*}{$\begin{array}{l}\text { Diabetes (total) } \\
\text { T2DM }\end{array}$} & Yes & 117 & 26.0 & 206 & 24.8 & \multirow[t]{2}{*}{0.651} \\
\hline & No & 333 & 74.0 & 623 & 75.2 & \\
\hline \multirow[t]{2}{*}{ T2DM (IDDM) } & Yes & 33 & 7.3 & 62 & 7.5 & \multirow[t]{2}{*}{0.924} \\
\hline & No & 417 & 92.7 & 767 & 92.5 & \\
\hline \multirow[t]{2}{*}{ T2DM (NIDDM) } & Yes & 69 & 15.3 & 122 & 14.7 & \multirow[t]{2}{*}{0.768} \\
\hline & No & 381 & 84.7 & 707 & 85.3 & \\
\hline \multirow[t]{2}{*}{ T2DM (dietary) } & Yes & 15 & 3.3 & 22 & 2.7 & \multirow[t]{2}{*}{0.489} \\
\hline & No & 435 & 96.7 & 807 & 97.3 & \\
\hline \multirow[t]{2}{*}{ Arterial hypertension } & Yes & 257 & 52.7 & 441 & 48.6 & \multirow[t]{2}{*}{0.150} \\
\hline & No & 231 & 47.3 & 466 & 51.4 & \\
\hline \multirow[t]{2}{*}{ Pulmonary } & Yes & 62 & 12.7 & 141 & 15.5 & \multirow[t]{2}{*}{0.151} \\
\hline & No & 426 & 87.3 & 766 & 84.5 & \\
\hline \multirow[t]{2}{*}{ Pulmonary embolism } & Yes & 3 & 0.6 & 5 & 0.6 & \multirow[t]{2}{*}{0.881} \\
\hline & No & 485 & 99.4 & 902 & 99.4 & \\
\hline \multirow{2}{*}{$\begin{array}{l}\text { Other cardiac and } \\
\text { vascular diseases }\end{array}$} & Yes & 44 & 9.0 & 83 & 9.2 & \multirow[t]{2}{*}{0.934} \\
\hline & No & 444 & 91.0 & 824 & 90.8 & \\
\hline \multirow[t]{2}{*}{ Reflux } & Yes & 67 & 13.7 & 197 & 21.7 & \multirow[t]{2}{*}{$<0.001$} \\
\hline & No & 421 & 86.3 & 710 & 78.3 & \\
\hline \multirow{2}{*}{$\begin{array}{l}\text { Degenerative } \\
\text { disease }\end{array}$} & Yes & 209 & 42.8 & 280 & 30.9 & \multirow[t]{2}{*}{$<0.001$} \\
\hline & No & 279 & 57.2 & 627 & 69.1 & \\
\hline \multirow[t]{2}{*}{ Varicoses } & Yes & 27 & 5.5 & 39 & 4.3 & \multirow[t]{2}{*}{0.301} \\
\hline & No & 461 & 94.5 & 868 & 95.7 & \\
\hline \multirow{2}{*}{$\begin{array}{l}\text { Non-Alcoholic } \\
\text { Steatohepatitis } \\
\text { (NASH) }\end{array}$} & Yes & 15 & 5.0 & 34 & 5.7 & \multirow[t]{2}{*}{0.670} \\
\hline & No & 286 & 95.0 & 566 & 94.3 & \\
\hline \multirow[t]{2}{*}{ Nicotine abuse } & Yes & 43 & 8.8 & 86 & 9.5 & \multirow[t]{2}{*}{0.680} \\
\hline & No & 445 & 91.2 & 821 & 90.5 & \\
\hline \multirow{2}{*}{$\begin{array}{l}\text { Degenerative skeletal } \\
\text { disease }\end{array}$} & Yes & 111 & 22.7 & 161 & 17.8 & \multirow[t]{2}{*}{0.025} \\
\hline & No & 377 & 77.3 & 746 & 82.2 & \\
\hline \multirow[t]{2}{*}{ Gonarthrosis } & Yes & 76 & 15.6 & 143 & 15.8 & \multirow[t]{2}{*}{0.925} \\
\hline & No & 412 & 84.4 & 764 & 84.2 & \\
\hline Sleep apnea & Yes & 90 & 18.4 & 116 & 12.8 & 0.005 \\
\hline & No & 398 & 81.6 & 791 & 87.2 & \\
\hline
\end{tabular}

\subsection{Operation data and time}

Because over $95 \%$ of surgeries were performed laparoscopically and the distribution of surgery type (laparoscopic vs. open vs. conversion) was not significant, we did not include surgery type in our analysis (Table 3). The mean operative time was significantly longer in R-RYGB patients than in R-SG patients $(160.3[158.8 ; 161.8]$ min vs. 128.3 [126.7; 129.8] $\min ; \mathrm{p}<0.001)$. 
Table 3 Operative data

\begin{tabular}{|c|c|c|c|c|c|}
\hline \multicolumn{6}{|c|}{ Type of surgery } \\
\hline & \multicolumn{2}{|c|}{ R-SG } & \multicolumn{2}{|c|}{ R-RYGB } & \multirow[t]{2}{*}{ p-value } \\
\hline & $\mathbf{n}$ & $\%$ & $\mathbf{n}$ & $\%$ & \\
\hline Laparotomy & 8 & 1.6 & 24 & 2.7 & \multirow[t]{3}{*}{0.398} \\
\hline Laparoscopy & 470 & 96.7 & 867 & 96.1 & \\
\hline Conversion & 8 & 1.6 & 11 & 1.2 & \\
\hline $\begin{array}{l}\text { Operative time [min]* } \\
\text { (Mean [range]) }\end{array}$ & \multicolumn{2}{|c|}{$\begin{array}{c}128.3 \\
{[126.7 ; 129.8]}\end{array}$} & \multicolumn{2}{|c|}{$\begin{array}{c}160.3 \\
{[158.8 ; 161.8]}\end{array}$} & $<0.001$ \\
\hline
\end{tabular}

\subsection{Intraoperative and postoperative complication rates and 30-day mortality:}

A total of 40 intraoperative complications were documented. 17 (3.5\%) of these complications occurred in the R-SG and $23(2.5 \%)$ in the R-RYGB. At p=0.321, there was no significant difference between the two groups. In detail, we analyzed the intraoperative injury of the liver $(p=0.173)$, spleen $(p=0.102)$ and bile duct, perforation of the stomach $(p=0.661)$, bleeding and occurrence of pneumothorax. With a p-value above 0.05 , there was no significant difference between the two groups in the occurrence of documented intraoperative complications. The details of complications are summarized in Table 4.

Table 4 Intraoperative complications

\begin{tabular}{|c|c|c|c|c|c|c|}
\hline & & \multicolumn{2}{|c|}{ R-SG } & \multicolumn{2}{|c|}{ R-RYGB } & \multirow[t]{2}{*}{ p-value } \\
\hline & & $\mathbf{n}$ & $\%$ & $\mathbf{n}$ & $\%$ & \\
\hline \multirow{2}{*}{$\begin{array}{l}\text { Intraoperative } \\
\text { complication (total) }\end{array}$} & Yes & 17 & 3.5 & 23 & 2.5 & \multirow[t]{2}{*}{0.312} \\
\hline & No & 471 & 96.5 & 884 & 97.5 & \\
\hline \multirow[t]{2}{*}{ Injury of splenic } & Yes & 5 & 1.0 & 3 & 0.3 & \multirow[t]{2}{*}{0.102} \\
\hline & No & 483 & 99.0 & 904 & 99.7 & \\
\hline \multirow[t]{2}{*}{ Injury of liver } & Yes & 1 & 0.2 & 0 & 0 & \multirow[t]{2}{*}{0.173} \\
\hline & No & 487 & 99.8 & 907 & 100 & \\
\hline \multirow[t]{2}{*}{ Pneumothorax } & Yes & 0 & 0 & 0 & 0 & \multirow[t]{2}{*}{ - } \\
\hline & No & 488 & 100 & 907 & 100 & \\
\hline \multirow[t]{2}{*}{ Perforation of the stomach } & Yes & 3 & 0.6 & 4 & 0.4 & \multirow[t]{2}{*}{0.661} \\
\hline & No & 485 & 99.4 & 903 & 99.6 & \\
\hline \multirow[t]{2}{*}{ Bile duct injury } & Yes & 0 & 0 & 0 & 0 & \multirow[t]{2}{*}{. } \\
\hline & No & 488 & 100 & 907 & 100 & \\
\hline \multirow[t]{2}{*}{ Vascular injury } & Yes & 1 & 0.2 & 0 & 0 & \multirow[t]{2}{*}{0.173} \\
\hline & No & 487 & 99.8 & 907 & 100 & \\
\hline \multirow[t]{2}{*}{ Bleeding } & Yes & 0 & 0 & 0 & 0 & \multirow[t]{2}{*}{. } \\
\hline & No & 488 & 100 & 907 & 100 & \\
\hline \multirow[t]{2}{*}{ Other } & Yes & 11 & 2.3 & 18 & 2.0 & \multirow[t]{2}{*}{0.736} \\
\hline & No & 477 & 97.7 & 889 & 98.0 & \\
\hline
\end{tabular}

The general and surgery-related postoperative complications were also analyzed. The general postoperative complications included urinary tract infections $(\mathrm{p}=0.182)$, cardiac $(\mathrm{p}=0.553)$, renal $(\mathrm{p}=0.249)$, and pulmonary complications $(\mathrm{p}=0.489)$, fever $(\mathrm{p}=0.596)$, and thrombosis $(\mathrm{p}=0.656)$. The total general postoperative complication rate was not significantly different between R-SG and R-RYGB ( $\mathrm{p}=0.621)$. There was no significant difference in the incidence of individual complications between the two groups with a p-value greater than 0.05 . An overview of the general postoperative complications is shown in Table 5. 
The specific postoperative complications (SPC) were bleeding requiring transfusion or surgical intervention, anastomotic and staple suture leakage and stenosis, ileus, sepsis, abscess formation, and peritonitis. The rate of total SPC was significantly lower in the R-SG than in the R-RYGB (5.1\% R-SG vs. 7.9\% R-RYGB; p=0.049). Notably, there was a significant difference in anastomotic stenosis rate in favor of R-SG (0.4\% vs. 2\%; $\mathrm{p}=0.018)$. No significant difference was found between the two groups regarding the incidence of abscess formation $(p=0.465)$, sepsis $(p=0.194)$, peritonitis $(\mathrm{p}=0.590)$, anastomotic leakage $(\mathrm{p}=0.794)$, bleeding requiring transfusion $(\mathrm{p}=0.754)$, bleeding requiring reoperation $(\mathrm{p}=0.221)$, and wound infection ( $\mathrm{p}=0.893)$. No significant difference was found in 30-day mortality between the two groups $(0.2 \%$ R-SG vs. $0.2 \%$ R-RYGB; $\mathrm{p}=0.952)$. Table 5 summarizes the general and specific postoperative complications.

Table 5 General and special postoperative complications

\begin{tabular}{|c|c|c|c|c|c|c|}
\hline & \multicolumn{2}{|c|}{ R-SG } & \multicolumn{2}{|c|}{ R-RYGB } & \multicolumn{2}{|c|}{ p-value } \\
\hline & $\mathbf{n}$ & $\%$ & $\mathbf{n}$ & $\%$ & & \\
\hline \multicolumn{7}{|c|}{ General postoperative complication } \\
\hline \multirow[t]{2}{*}{ Total } & Yes & 30 & 6.1 & 62 & 6.8 & \multirow[t]{2}{*}{0.621} \\
\hline & No & 458 & 93.9 & 845 & 93.2 & \\
\hline \multirow[t]{2}{*}{ Urinary tract infection } & Yes & 2 & 0.4 & 10 & 1.1 & \multirow[t]{2}{*}{0.182} \\
\hline & No & 486 & 99.6 & 897 & 98.9 & \\
\hline \multirow[t]{2}{*}{ Cardiac complication } & Yes & 2 & 0.4 & 6 & 0.7 & \multirow[t]{2}{*}{0.553} \\
\hline & No & 486 & 99.6 & 901 & 99.3 & \\
\hline \multirow[t]{2}{*}{ Renal complication } & Yes & 2 & 0.4 & 1 & 0.1 & \multirow[t]{2}{*}{0.249} \\
\hline & No & 486 & 99.6 & 906 & 99.9 & \\
\hline \multirow[t]{2}{*}{ Pulmonary complication } & Yes & 10 & 2.0 & 14 & 1.5 & \multirow[t]{2}{*}{0.489} \\
\hline & No & 478 & 98.0 & 893 & 98.5 & \\
\hline \multirow[t]{2}{*}{ Fever } & Yes & 10 & 2.0 & 15 & 1.7 & \multirow[t]{2}{*}{0.596} \\
\hline & No & 478 & 98.0 & 892 & 98.3 & \\
\hline \multirow[t]{2}{*}{ Thrombosis } & Yes & 1 & 0.2 & 1 & 0.1 & \multirow[t]{2}{*}{0.656} \\
\hline & No & 487 & 99.8 & 906 & 99.9 & \\
\hline \multirow[t]{2}{*}{ Other } & Yes & 15 & 3.1 & 31 & 3.4 & \multirow[t]{2}{*}{0.731} \\
\hline & No & 473 & 96.9 & 876 & 96.6 & \\
\hline \multicolumn{7}{|c|}{ Special postoperative complication } \\
\hline \multirow[t]{2}{*}{ Total } & Yes & 25 & 5.1 & 72 & 7.9 & \multirow[t]{2}{*}{0.049} \\
\hline & No & 463 & 94.9 & 835 & 92.1 & \\
\hline \multirow[t]{2}{*}{ Bleeding requiring transfusion } & Yes & 6 & 1.2 & 13 & 1.4 & \multirow[t]{2}{*}{0.754} \\
\hline & No & 482 & 98.8 & 894 & 98.6 & \\
\hline \multirow[t]{2}{*}{ Bleeding requiring surgery } & Yes & 3 & 0.6 & 12 & 1.3 & \multirow[t]{2}{*}{0.221} \\
\hline & No & 485 & 99.4 & 895 & 98.7 & \\
\hline \multirow[t]{2}{*}{ Anastomotic and staple line leak } & Yes & 9 & 1.8 & 15 & 1.7 & \multirow[t]{2}{*}{0.794} \\
\hline & No & 479 & 98.2 & 892 & 98.3 & \\
\hline \multirow[t]{2}{*}{ Stenosis } & Yes & 2 & 0.4 & 18 & 2.0 & \multirow[t]{2}{*}{0.018} \\
\hline & No & 486 & 99.6 & 889 & 98.0 & \\
\hline
\end{tabular}




\begin{tabular}{|c|c|c|c|c|c|c|}
\hline & \multicolumn{2}{|c|}{ R-SG } & \multicolumn{2}{|c|}{ R-RYGB } & \multicolumn{2}{|c|}{ p-value } \\
\hline & $\mathbf{n}$ & $\%$ & $\mathbf{n}$ & $\%$ & & \\
\hline \multicolumn{7}{|c|}{ General postoperative complication } \\
\hline \multirow[t]{2}{*}{ Ileus } & Yes & 0 & 0 & 6 & 0.7 & \multirow[t]{2}{*}{0.072} \\
\hline & No & 488 & 100 & 901 & 99.3 & \\
\hline \multirow[t]{2}{*}{ Abscess formation } & Yes & 5 & 1.0 & 6 & 0.7 & \multirow[t]{2}{*}{0.465} \\
\hline & No & 483 & 99.0 & 901 & 99.3 & \\
\hline \multirow[t]{2}{*}{ Sepsis } & Yes & 5 & 1.0 & 4 & 0.4 & \multirow[t]{2}{*}{0.194} \\
\hline & No & 483 & 99.0 & 903 & 99.6 & \\
\hline \multirow[t]{2}{*}{ Peritonitis } & Yes & 3 & 0.6 & 8 & 0.9 & \multirow[t]{2}{*}{0.590} \\
\hline & No & 485 & 99.4 & 899 & 99.1 & \\
\hline \multirow[t]{2}{*}{ Wound infection } & Yes & 5 & 1.0 & 10 & 1.1 & \multirow[t]{2}{*}{0.893} \\
\hline & No & 483 & 99.0 & 897 & 98.9 & \\
\hline \multirow[t]{2}{*}{ 30-day mortality } & Yes & 1 & 0.2 & 2 & 0.2 & \multirow[t]{2}{*}{0.952} \\
\hline & No & 486 & 99.8 & 903 & 99.8 & \\
\hline
\end{tabular}

\section{Discussion}

Since January 1, 2005, primary and repeat bariatric procedures have been recorded by the Institute for Quality Assurance Surgical Medicine at Otto-von-Guericke University Magdeburg as part of a quality assurance study on the surgical treatment of obesity to improve the quality of care. A comparison was made between patients with R-SG and R-RYGB after failed AGB.

Adjustable gastric banding (AGB) is one of the well-known bariatric surgical procedures [17]. According to various literature results, there are many advantages for using adjustable gastric banding for obesity treatment $[18,19]$. One study [20] reported a permanent change in BMI with $47 \%$ EWL maintained for up to 15 years after AGB. However, due to the disadvantages of AGB and complications, the surgery rate has decreased in Europe and worldwide [21]. For this reason, several clinical trials recommend switching to other bariatric procedures to eliminate the complication or achieve a significant \%TWL in patients with obesity $[22,23,24,25,26]$. The primary documented indications for removal of a failed gastric band were dysphagia, weight regain, band slippage, band erosion, band defect, and band sepsis $[27,28]$. Therefore, due to the high risks of revision surgery, reoperation after failed bariatric surgery must be done in consultation with the patient [29]. Regarding revision surgery after AGB, there is no strict consensus on the optimal conversion method after failed AGB procedure. Some options, including band repositioning or conversion to other surgical procedures such as SG or RYBG, have been proposed [21,30].

Since SG and RYGB are adequate procedures in Germany, switching from AGB to SG or RYGB is an exciting option for revision operations $[31,32,33]$. However, there are still no clear guidelines for conversion from AGB to RYGB and SG $[34,35,36]$ and statements in the literature vary regarding the effectiveness of both surgical procedures $[37,38,39]$. Chansaenroj et al. [40] analyzed data from 275 patients after revision surgery of a failed AGB. Several factors, including percent excess weight loss at 10-year follow-up, revision surgery, and major complication, were considered. 53 patients (19.3\%) had revision surgery (26 single anastomosis (mini-)gastric bypass (R-LSAGB), 17 sleeve gastrectomy (R-LSG), 9 Roux-en-Y gastric bypass (R-LRYGB), and another procedure). After revision surgery, there was a significant excess weight loss (EWL \%) of over $50 \%$ compared to $45 \%$ in the post-gastric banding group at 10 -year follow-up. In the conclusion of the study, the authors stated that revision surgery of failed AGB is safe and can be performed without increased complication rate. In our study, we did not analyze the effect of R-RYGB and R-SG on the change in BMI and EWL\%. This should be done in other studies with long-term follow-up after revision surgery. In addition, we only analyzed the outcome of both surgical interventions (SG and RYGB). All other surgical interventions were not included in our analysis.

In the present study, data from 1395 patients between 2005 and 2019 were analyzed. Moreover, we analyzed shortterm outcomes after SG and RYGB as revision surgery after failed AGB. With a total of 907 patients with R-RYGB and 
488 patients with R-SG, our study represents a large reported series of RYGB and SG after failed AGB. Our study aims to investigate whether RYGB or SG is superior to revision surgery after failed AGB. The decision for R-SG or R-RYGB depends on the surgeon's experience, risk factors, and comorbidities. In our study, the reason for the choice of procedure (laparotomy, laparoscopy, and conversion, SG or RYGB), removal of the gastric band, and surgeon's experience in performing SG or RYGB were not studied. In the present study, a significant distribution of demographic aspects was found between the two groups. Patients in the R-SG were heavier than those in the R-RYGB, with a mean BMI of $45.8 \% \mathrm{~kg} / \mathrm{m}^{2}$ (44\%; $\left.\mathrm{p}=0.001\right)$. The reason for this distribution and the effect of BMI on postoperative outcomes were not investigated. The overall comorbidity rate was not significantly different between the two groups. However, more patients in the R-SG suffered from sleep apnea than patients in the R-RYGB.

In contrast, patients in the R-RYGB had a higher ASA classification than patients in the R-SG. While patients in the RRYGB group had a lower incidence of DSD and degenerative skeletal disease, patients in the R-SG group had fewer reflux symptoms than patients in the R-RYGB group. Other comorbidities analyzed were not individually significant between the two groups. It was also noted that the number of female patients was a large proportion compared to the number of male patients in both groups. The reason for this distribution could be that a large proportion of male patients are operated only when they have severe obesity-associated diseases. However, this is only our conjecture. The study did not thoroughly investigate the reason for the difference in gender distribution and the effect on postoperative outcome. However, Stroh et al. [41] examined the influence of gender on postoperative outcomes after bariatric surgery. Anastomotic leakage, gastric perforation, bleeding, wound infection, and stenosis were analyzed. Special complications occurred in $4.87 \%$ of patients after SG and in $5.30 \%$ of patients after RYGB. Overall, the number of special complications was significantly higher in men than in women $(\mathrm{p}=0.001)$.

Despite the advantages of the two surgical methods as primary and secondary surgery [42, 43] some disadvantages are usually expected after the two surgical procedures and should be considered when performing revision surgery [44, 45]. Theunissen and colleagues [46] compared the postoperative outcome of 107 patients with RYGB as revision surgery after AGB failure with 1020 primary RYGB (P-RYGB). Complications ranged from wound infections, urinary tract infections, cardiopulmonary to anastomotic leakage and reoperation. There was no significant difference in major complication rate ( 2.8 vs. $2.3 \%, p=0.73$ ) between R-RYGB and P- RYGB. Cadière et al. [47] retrospectively compared early and late complications after P-RYGB vs. R-RYGB between January 2004 and August 2008. The median preoperative BMI was $42 \mathrm{~kg} / \mathrm{m}^{2}$ for P-RYGB and $39 \mathrm{~kg} / \mathrm{m}^{2}$ for R-RYGB ( $\left.\mathrm{p}=0.002\right)$. Early complications occurred in 24 patients (22.2\%) after R-RYGB and in 37 patients $(10.2 \%)$ after P-RYGB $(\mathrm{p}<0.001)$. Late complications occurred significantly more frequently after R-RYGB than after P-RYGB (30.6\% vs. 12.7\%; $<<0.001$ ). Mognol et al. [48] analyzed data from 70 patients who underwent R-RYGB after failed AGB. Indications for band removal were weight regain, inadequate weight loss, gastric band migration, and symptomatic proximal gastric pouch dilatation, and psychological band intolerance. $14.3 \%$ of patients developed an early complication, and $8.6 \%$ developed a late major complication. The author found that RYGB can be used as a revision procedure with acceptable long- and short-term outcomes after failed AGB. Yazbek et al. [49] analyzed postoperative outcomes after R-SG compared with P-SG. 800 patients were included in the study. 90 out of 800 patients underwent revision surgery SG after failed AGB. Complications and percent excess weight loss (\%EWL) were analyzed. The author found that the postoperative complication rate was higher after R-SG than after PSG. Despite this complication rate, SG provides a positive outcome as a revision surgery after failed AGB. One study [50] compared data from 32 patients after R-SG with 64 patients after P-SG. The 30-day complication rate was higher in the R-SG group than in the P-SG group (14.71\% vs. 6.25). The length of hospital stay was 3.22 days in the R-SG vs. 2.59 days in the P-SG. In addition, several clinical trials have compared the long- and short-term outcomes of R-RYGB and R-SG $[49,51]$. In our study, we did not compare the results of primary surgery with those of revision surgery. We only focused on the outcomes of both procedures as revision surgery after failed AGB.

Janik et al. [11] investigated the safety of R-SG and R-RYGB after failed laparoscopic adjustable gastric banding (LAGB). 2708 patients were included in the study. The anastomotic leakage rate was higher in R-RYGB than in R-SG $(2.07 \%$ vs. $1.18 \%, \mathrm{p}=0.070)$. The incidence of bleeding was significantly higher in the R-RYGB group than in the R-SG group (2.66\% vs. $0.44 \%, \mathrm{p}<0.001)$. This was also true for the 30 -day readmission rate $(7.46 \%$ in the R-RYGB vs. $3.69 \%$ in the R-SG; p<0.001), 30-day reoperation (3.25\% vs. $1.26 \%, p<0.001)$, and length of hospital stay. The study showed a significant difference in terms of postoperative outcomes in favor of R-SG. Angrisani et al. [52] reported comparable results in terms of postoperative outcomes after SG and RYGB as revision surgery after failed AGB. No significant differences were documented between the two groups in terms of BMI change and percent excess weight loss. The present study compared the short-term outcome after revision surgery between the two surgical procedures (R-SG and R-RYGB). Long-term outcomes were not investigated in our study. The distribution of total intraoperative complication rate was different between the two groups in our analysis. With a p-value above 0.05 , there was no significant overall difference between the two groups in the occurrence of documented intraoperative complications. 
The general postoperative complications ranged from urinary tract infections, cardiac, renal, and pulmonary complications, fever, and the occurrence of thrombosis. With a p-value greater than 0.05, there was no significant difference between the two groups in the overall complication rate. The rate of total SPC was significantly lower in the R-SG than in the R-RYGB in the two groups. In addition, there was a significant difference between the two groups in terms of the rate of occurrence of total specific postoperative complications in favor of R-SG. There was a significant difference in anastomotic stenosis rate in favor of R-SG. Other specific postoperative complications showed no significant disadvantages between the two groups.

Operative time differed significantly between the two groups, with the least time in the R-SG. Several clinical studies analyzed 30-day mortality after R-SG and R-RYGB. Here, both procedures showed similar results in this regard [53, 54]. Our analysis shows similar results. There was no significant difference regarding 30-day mortality after R-SG compared to R-RYGB.

\section{Conclusion}

A failed AGB is best treated with conversion to another bariatric procedure. The present study found that conversion to RYGB and SG can be performed for failed AGB with nearly comparable postoperative outcomes. In the short term, primary surgery appears to have the lowest intervention-related complication rates. However, R-SG showed lower intervention-related complication rates than R-RYGB. No significant differences were documented between R-SG and R-RYGB regarding intraoperative and general postoperative complications. This was also true for 30-day mortality. The mean operative time was significantly lower in the R-SG than in the R-RYGB group.

RYGB and SG as redo procedures after failed AGB are safe and beneficial. R-SG and R-RYGB provide a great outcome in terms of intraoperative and postoperative complication rates. Despite the advantages of both procedures, we cannot recommend any procedure in our study. However, it should be noted that proper patient selection is essential to avoid such possible adverse complications. The indication should be individualized depending on the intraoperative findings and the general condition of the patient. In addition, patients should be informed in detail about the advantages and disadvantages of both procedures. Due to the retrospective nature of the studies, these results should be interpreted with caution. Regarding long-term results, further studies with higher methodological quality are necessary.

\section{Compliance with ethical standards}

\section{Acknowledgments}

All authors equally contributed and acknowledge to read and approved the study.

\section{Disclosure of conflict of interest}

The authors declare that this article has not received funds from any entity, for its preparation and publication; and we have no conflicts of interest.

\section{Statement of ethical approval}

For this type of retrospective study, no formal consent was required. All data were gathered and analyzed in accordance with the privacy and ethical standards of the institutional and national research committee and with the 1964 Helsinki declaration and its later amendments or comparable ethical standards.

\section{Statement of informed consent}

Informed consent was obtained from all individual participants included in the study.

\section{References}

[1] Hruby A, Hu FB. The Epidemiology of Obesity: A Big Picture. Pharmacoeconomics. 2015; 33(7) :673-689.

[2] Francesco Branca, Haik Nikogosian and Tim Lobstein. WHO: The obesity challenge and strategies to combat it in WHO European Region. Denmark. 2007. https://www.euro.who.int/_data/assets/pdf_file/0008/98243/E89858.pdf 
[3] Yumuk V, Tsigos C, Fried M, et al. European Guidelines for Obesity Management in Adults. Obes Facts. 2015;8(6):402-424.

[4] Mannucci E, Petroni ML, Villanova N, et al. Clinical and psychological correlates of health-related quality of life in obese patients. Health Qual Life Outcomes. 2010; 8: 90.

[5] Kennedy RL, Chokkalingham K, Srinivasan R. Obesity in the elderly: who should we be treating, and why, and how? Curr Opin Clin Nutr Metab Care. 2004; 7(1): 3-9.

[6] Colquitt JL, Pickett K, Loveman E, Frampton GK. Surgery for weight loss in adults. Cochrane Database Syst Rev. 2014; 8: CD003641.

[7] Breneise, R., Schütz, T., Sänger, S. \& Luck-Sikorski. Surgery of obesity and Metabolic Diseases - Preparation of a Patient Guideline Based on the S3 guideline. Abstracts of Obesity Congress 2020 to the 36th Annual Meeting of German Obesity Society (DAG). 2020. https://www.awmf.org/uploads/tx_szleitlinien/088-001p_S3_ChirurgieAdipositas-metabolische-Erkrankugen_2020-06.pdf

[8] Noel P, Schneck AS, Nedelcu M, et al. Laparoscopic sleeve gastrectomy as a revisional procedure for failed gastric banding: lessons from 300 consecutive cases. Surg Obes Relat Dis. 2014; 10(6): 1116-1122.

[9] Elnahas A, Graybiel K, Farrokhyar F, Gmora S, Anvari M, Hong D. Revisional surgery after failed laparoscopic adjustable gastric banding: a systematic review. Surg Endosc. 2013; 27(3): 740-745.

[10] Alratrout H, Almuttawa A, Siciliano I, Keller P. Laparoscopic Roux-en-Y Gastric Bypass for Failed Gastric Banding: One-Step or Two-Step Revisional Surgery?. Obes Surg. 2021; 31(2): 646-653.

[11] Janik MR, Rogula TG, Mustafa RR, Alhaj Saleh A, Khaitan L. Safety of Revision Sleeve Gastrectomy Compared to Roux-Y Gastric Bypass After Failed Gastric Banding: Analysis of the MBSAQIP. Ann Surg. 2019; 269(2): 299-303.

[12] Tran TT, Pauli E, Lyn-Sue JR, Haluck R, Rogers AM. Revisional weight loss surgery after failed laparoscopic gastric banding: an institutional experience. Surg Endosc. 2013; 27(11): 4087-4093.

[13] Moon RC, Teixeira AF, Jawad MA. Conversion of failed laparoscopic adjustable gastric banding: sleeve gastrectomy or Roux-en-Y gastric bypass? Surg Obes Relat Dis. 2013; 9(6): 901-907.

[14] Wu C, Wang FG, Yan WM, Yan M, Song MM. Clinical Outcomes of Sleeve Gastrectomy versus Roux-En-Y Gastric Bypass after Failed Adjustable Gastric Banding. Obes Surg. 2019; 29(10): 3252-3263.

[15] Gittelsohn J, Trude A. Diabetes and obesity prevention: changing the food environment in low-income settings. Nutr Rev. 2017; 75(1): 62-69.

[16] Flynn MA, McNeil DA, Maloff B, et al. Reducing obesity and related chronic disease risk in children and youth: a synthesis of evidence with 'best practice' recommendations. Obes Rev. 2006; 7(1): 7-66.

[17] Tice JA, Karliner L, Walsh J, Petersen AJ, Feldman MD. Gastric banding or bypass? A systematic review comparing the two most popular bariatric procedures. Am J Med. 2008; 121(10): 885-893.

[18] Hopkins JC, Blazeby JM, Rogers CA, Welbourn R. The use of adjustable gastric bands for management of severe and complex obesity. Br Med Bull. 2016; 118(1): 64-72.

[19] Galal AM, Boerma EJ, Fransen S, et al. Impact of Laparoscopic Banded Gastric Bypass on Weight Loss Surgery Outcomes: 5 Years' Experience. Obes Surg. 2020; 30(2): 630-639.

[20] O'Brien PE, McPhail T, Chaston TB, Dixon JB. Systematic review of medium-term weight loss after bariatric operations. Obes Surg. 2006; 16(8): 1032-1040.

[21] Kowalewski PK, Olszewski R, Kwiatkowski A, Gałązka-Świderek N, Cichoń K, Paśnik K. Life with a Gastric Band. Long-Term Outcomes of Laparoscopic Adjustable Gastric Banding-a Retrospective Study. Obes Surg. 2017; 27(5): 1250-1253.

[22] Topart P, Becouarn G, Ritz P. Biliopancreatic diversion with duodenal switch or gastric bypass for failed gastric banding: retrospective study from two institutions with preliminary results. Surg Obes Relat Dis. 2007; 3(5): 521525.

[23] Abu-Gazala S, Keidar A. Conversion of failed gastric banding into four different bariatric procedures. Surg Obes Relat Dis. 2012; 8(4): 400-407. 
[24] Sharples AJ, Charalampakis V, Daskalakis M, Tahrani AA, Singhal R. Systematic Review and Meta-Analysis of Outcomes After Revisional Bariatric Surgery Following a Failed Adjustable Gastric Band. Obes Surg. 2017; 27(10): 2522-2536.

[25] Falk V, Sheppard C, Kanji A, Birch D, Karmali S, de Gara C. The fate of laparoscopic adjustable gastric band removal. Can J Surg. 2019; 62(5): 328-333.

[26] Stroh C, Benedix D, Weiner R, et al. Is a one-step sleeve gastrectomy indicated as a revision procedure after gastric banding? Data analysis from a quality assurance study of the surgical treatment of obesity in Germany. Obes Surg. 2014; 24(1): 9-14.

[27] Lecot FP, Boerma EG, Sigterman-Nelissen R, Meesters B, Fransen S, Greve JW. Conversion of Adjustable Gastric Banding to Adjustable Banded Roux-en-Y Gastric Bypass: Should We Leave the Band in Place? Obes Surg. 2019; 29(12): 3912-3918.

[28] Vitiello A, Berardi G, Velotti N, De Palma GD, Musella M. Is there an indication left for gastric band? A single center experience on 178 patients with a follow-up of 10 years. Updates Surg. 2021; 73(2): 657-662.

[29] Aarts E, Koehestanie P, Dogan K, Berends F, Janssen I. Revisional surgery after failed gastric banding: results of one-stage conversion to RYGB in 195 patients. Surg Obes Relat Dis. 2014; 10(6): 1077-1083.

[30] Ardestani A, Lautz DB, Tavakkolizadeh A. Band revision versus Roux-en-Y gastric bypass conversion as salvage operation after laparoscopic adjustable gastric banding. Surg Obes Relat Dis. 2011; 7(1): 33-37.

[31] Pearlstein S, Sabrudin SA, Shayesteh A, Tecce ER, Roslin M. Outcomes After Laparoscopic Conversion of Failed Adjustable Gastric Banding (LAGB) to Laparoscopic Sleeve Gastrectomy (LSG) or Single Anastomosis Duodenal Switch (SADS) [published correction appears in Obes Surg. 2019 Mar 7;:]. Obes Surg. 2019;29(6):1726-1733.

[32] Pencovich N, Lahat G, Goldray O, Abu-Abeid S, Klausner JM, Meron Eldar S. Safety and Outcome of Laparoscopic Sleeve Gastrectomy Following Removal of Adjustable Gastric Banding: Lessons from 109 Patients in a Single Center and Review of the Literature. Obes Surg. 2017; 27(5): 1266-1270.

[33] Van Nieuwenhove Y, Ceelen W, Van Renterghem K, Van de Putte D, Henckens T, Pattyn P. Conversion from band to bypass in two steps reduces the risk for anastomotic strictures. Obes Surg. 2011; 21(4): 501-505.

[34] Langer FB, Bohdjalian A, Shakeri-Manesch S, et al. Inadequate weight loss vs secondary weight regain: laparoscopic conversion from gastric banding to Roux-en-Y gastric bypass. Obes Surg. 2008; 18(11): 1381-1386.

[35] te Riele WW, Sze YK, Wiezer MJ, van Ramshorst B. Conversion of failed laparoscopic gastric banding to gastric bypass as safe and effective as primary gastric bypass in morbidly obese patients. Surg Obes Relat Dis. 2008; 4(6): 735-739.

[36] Dietch ZC, Schirmer BD, Hallowell PT. Simultaneous conversion of gastric band to sleeve gastrectomy is associated with increased postoperative complications: an analysis of the American College of Surgeons National Surgical Quality Improvement Program. Surg Endosc. 2017; 31(12): 5228-5233.

[37] Uittenbogaart M, Leclercq WK, Luijten AA, van Dielen FM. Laparoscopic Adjustable Gastric Banding After Failed Roux-En-Y Gastric Bypass. Obes Surg. 2017; 27(2): 381-386.

[38] Walker DM, Hii MW, Skinner CE, Hopkins GH. Roux-en-Y gastric bypass after successful weight loss with a laparoscopic adjustable gastric band: rationales and early outcomes in patients of body mass index $<35 \mathrm{~kg} / \mathrm{m}$ (2.). Surg Obes Relat Dis. 2014; 10(6): 1104-1108.

[39] Carandina S, Maldonado PS, Tabbara M, et al. Two-step conversion surgery after failed laparoscopic adjustable gastric banding. Comparison between laparoscopic Roux-en-Y gastric bypass and laparoscopic gastric sleeve. Surg Obes Relat Dis. 2014; 10(6): 1085-1091.

[40] Chansaenroj P, Aung L, Lee WJ, Chen SC, Chen JC, Ser KH. Revision Procedures after Failed Adjustable Gastric Banding: Comparison of Efficacy and Safety. Obes Surg. 2017; 27(11): 2861-2867.

[41] Stroh C, Weiner R, Wolff S, Knoll C, Manger T; Obesity Surgery Working Group and Competence Network Obesity. Are There Gender-Specific Aspects in Obesity and Metabolic Surgery? Data Analysis from the German Bariatric Surgery Registry. Viszeralmedizin. 2014; 30(2): 125-132.

[42] Thomopoulos T, Podetta M, Studer AS, et al. Efficiency of Laparoscopic One-Step Revision of Failed Adjusted Gastric Banding to Gastric Sleeve: a Retrospective Review of 101 Consecutive Patients. Obes Surg. 2019; 29(12): 3868-3873. 
[43] Marti-Fernandez R, Cassinello-Fernandez N, Cuenca-Ramirez MD, et al. Roux-en-Y Gastric Bypass as an Effective Bariatric Revisional Surgery after Restrictive Procedures. Obes Facts. 2020; 13(3): 367-374.

[44] Skogar ML, Sundbom M. Early complications, long-term adverse events, and quality of life after duodenal switch and gastric bypass in a matched national cohort. Surg Obes Relat Dis. 2020; 16(5): 614-619.

[45] Lazzati A, Bechet S, Jouma S, Paolino L, Jung C. Revision surgery after sleeve gastrectomy: a nationwide study with 10 years of follow-up. Surg Obes Relat Dis. 2020; 16(10): 1497-1504.

[46] Theunissen CM, Guelinckx N, Maring JK, Langenhoff BS. Redo Laparoscopic Gastric Bypass: One-Step or Two-Step Procedure? Obes Surg. 2016; 26(11): 2675-2682.

[47] Cadière GB, Himpens J, Bazi M, et al. Are laparoscopic gastric bypass after gastroplasty and primary laparoscopic gastric bypass similar in terms of results? Obes Surg. 2011; 21(6): 692-698.

[48] Mognol P, Chosidow D, Marmuse JP. Laparoscopic conversion of laparoscopic gastric banding to Roux-en-Y gastric bypass: a review of 70 patients. Obes Surg. 2004; 14(10): 1349-1353.

[49] Yazbek T, Safa N, Denis R, Atlas H, Garneau PY. Laparoscopic sleeve gastrectomy (LSG)-a good bariatric option for failed laparoscopic adjustable gastric banding (LAGB): a review of 90 patients. Obes Surg. 2013; 23(3): 300305.

[50] Barrett AM, Vu KT, Sandhu KK, Phillips EH, Cunneen SA, Burch MA. Primary sleeve gastrectomy compared to sleeve gastrectomy as revisional surgery: weight loss and complications at intermediate follow-up. J Gastrointest Surg. 2014; 18(10): 1737-1743.

[51] Marin-Perez P, Betancourt A, Lamota M, Lo Menzo E, Szomstein S, Rosenthal R. Outcomes after laparoscopic conversion of failed adjustable gastric banding to sleeve gastrectomy or Roux-en-Y gastric bypass. Br J Surg. 2014; 101(3): 254-260.

[52] Angrisani L, Vitiello A, Santonicola A, Hasani A, De Luca M, Iovino P. Roux-en-Y Gastric Bypass Versus Sleeve Gastrectomy as Revisional Procedures after Adjustable Gastric Band: 5-Year Outcomes. Obes Surg. 2017; 27(6): 1430-1437.

[53] Janik M, Ibikunle C, Khan A, Aryaie AH. Safety of Single Stage Revision Laparoscopic Sleeve Gastrectomy Compared to Laparoscopic Roux-Y Gastric Bypass after Failed Gastric Banding. Obes Surg. 2021; 31(2): 588-596.

[54] Jennings NA, Boyle M, Mahawar K, Balupuri S, Small PK. Revisional laparoscopic Roux-en-Y gastric bypass following failed laparoscopic adjustable gastric banding. Obes Surg. 2013; 23(7): 947-952. 